\title{
An eighteen month old boy with cystinuria and urolithiasis
}

\author{
A M Abeygunasekera ${ }^{1}$, M B A L P Wijesuriye ${ }^{2}$ \\ Sri Lanka Journal of Child Health, 2003; 32: 23-4
}

(Key words: cystinuria, urolithiasis)

\section{Introduction}

Cystinuria is an autosomal recessive disorder with a defect in transport of cystine and other dibasic aminoacids by the epithelial cells of the renal tubules and small intestine ${ }^{1}$. The increased urinary excretion of cystine, the least soluble of all aminoacids, especially within the range of normal urinary $\mathrm{pH}$, results in its crystallization and stone formation. Cystine stones occur only in patients with cystinuria and account for up to $10 \%$ of those occurring in children $^{1,2}$.

\section{Case report}

A mother brought her 18 month old son to the paediatric clinic for straining while passing urine and poor stream for the last six months. Ultrasonography of the urinary tract revealed renal and bladder calculi. An x-ray of the kidneys, ureters and bladder confirmed the presence of multiple calculi in the bladder (Figure 1).

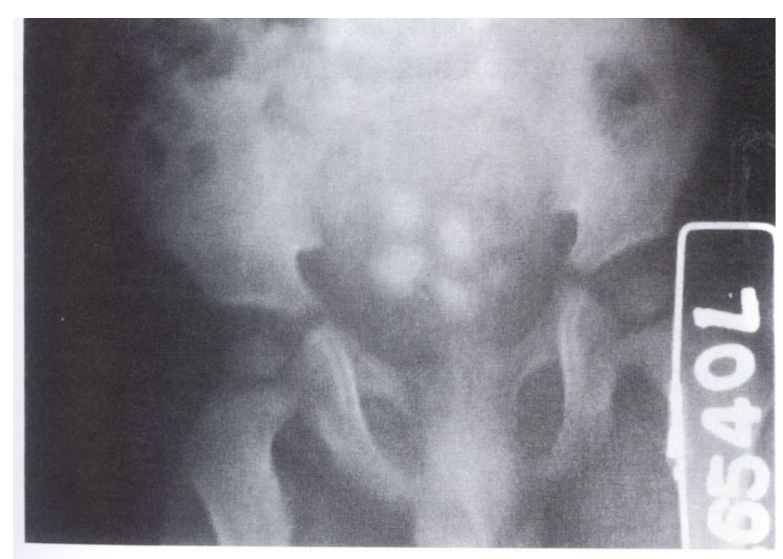

Figure 1. Multiple stones in the bladder

Five stones measuring $1-3 \mathrm{~cm}$ were removed from the bladder at vesicolithotomy. The stones were composed of cystine and calcium oxalate, when analysed.

\section{${ }^{1}$ Consultant Urological Surgeon, ${ }^{2}$ Consultant Paediatrician, Colombo North Teaching Hospital.}

(Received on 20 July 2002)
Microscopy of the urine sediments showed cystine crystals. His serum calcium level was normal. The twenty-four hour urinary aminoacid excretion study could not be performed. After operation child's urinary symptoms resolved.

\section{Discussion}

Although less common in Asians, cystinuria should be considered in every child with urolithiasis because of its lifelong duration and the likelihood of recurrent urinary stones.

The simplest screening test is microscopic examination of the sediments of the first morning urinary specimen for typical benzene ring shaped cystine crystals ${ }^{1}$. Although diagnostic, crystals are found in only about $20 \%$ of patients ${ }^{2}$. The screening test using colorimetry is not available in Sri Lanka. Patients who show a positive screening test should be evaluated further with 24-hour urinary aminoacid chromatography to quantify the urinary cystine

excretion. There may be associated calcium and uric acid stones since hypercalciuria and hyperuricosuria can accompany cystinuria ${ }^{3}$.

Patients with infected, symptomatic or obstructing stones require surgical intervention. The results of extracorporeal shock wave lithotripsy (ESWL) to fragment the cystine stones is less successful ${ }^{4}$. Since the recurrence rate is high, surgical treatment should not be used excessively. If compelled to do so, minimal access surgical procedures are preferred.

Non-surgical treatment is aimed at dissolution of uncomplicated, small calculi and prevention of new stone formation. It is essential to increase the urine volume by increasing oral fluid intake above 1.5-2.0 $\mathrm{L} / \mathrm{m}^{2}$ (3-4 L/day in adults). Maintaining the diuresis even in the night is vital for its success ${ }^{5}$.

Although dietary sodium and methionine restriction reduces urinary cystine excretion, it is not recommended for children due to its adverse effects on growth $^{1,6}$. Cystine solubility can be increased by urinary alkalinisation with potassium citrate (15- 
20mmol/ day). Sodium carbonate and sodium citrate are less popular due to the presence of sodium ${ }^{7}$. Acetazolamide can be used to augment the alkalinization $^{8}$.

D-penicillamine is an effective chelator which reduces cystine stone formation. But its use is limited by the high incidence of serious side effects ${ }^{7}$. Recently captopril has been used to increase the solubility of cystine in these patients ${ }^{9}$. Whatever the choice, medical therapy is life long and compliance is a problem especially in children.

\section{References}

1. Menon M, Parulkar B G, Drach G W. Urinary lithiasis: etiology, diagnosis and medical management. In: Walsh $\mathrm{P} C$, Retik $\mathrm{A} B$, Vaughan E D, Wein A J; eds. Campbell's Urology. 7th ed. London: W B Saunders; 1998; 2661-733.

2. Evans W P, Resnick M 1, Boyce W H. Homozygous cystinuria: Evaluation of 35 patients. The Journal of Urology 1982; 127:7079.

3. Salchaee K, Poindexter J R, Pak C Y. The spectrum of metabolic abnormalities in patients with cystine nephrolithiasis. The Journal of Urology 1989; 141 (4): 819-21.
4. Singer A, Das S. Cystinuria: a review of the pathophysiology and management. The Journal of Urology 1989; 142:669-73.

5. AI-Hermi B, AI-Karneli A, Aal A A. Cystinuria in children in Bahrain. Saudi Journal of Kidney Diseases and Transplantation 2002;13:171-5.

6. Barbey F, Joly D, Rieu P, Mejean A, Dandon M, Jungers $P$. Medical treatment of cystinuria: Critical appraisal of long term results. The Journal of Urology 2000; 163: 1419-23.

7. Harbar J A, Cusworth D C, Lawes L C, Wrong O M. Comparison of 2mercaptopropionylglycine and D-penicillamine in the treatment of cystinuria. The Journal of Urology 1986; 136:146-9.

8. Freed S Z. The alternating use of an alkaline salt and acetazolamide in the management of cystine and uric acid stones. The Journal of Urology 1975; 113: 96-9.

9. Perazella M A, Buller G K. Successful treatment of cystinuria with captopril. American Journal of Kidney Disease 1993; 21: 504-7. 
